\title{
Hematological Manifestations of Infectious Disease
}

\author{
Aravind Raj Sanjeevaiah MD*, Santhosh Sadashiv MD, Divya Bhargavi Mella MD, Neeta Pathe MD and Mary \\ Claire Maxwell NP-C
}

Assistant Professor, Department of Internal Medicine, Harold C. Simmons Comprehensive Cancer Center, USA

Submission: May 20, 2018; Published: May 29, 2018

*Corresponding author: Aravind Raj Sanjeevaiah MD, Assistant Professor, Department of Internal Medicine, Harold C. Simmons Comprehensive Cancer Center, USA, Tel: 4013597531; Email: Aravind.Sanjeevaiah@UTSouthwestern.edu

\section{Abstract}

Infectious processes have a potential to complicate the clinical picture by triggering a cascade of events which can ultimately affect standard lab values. Red blood cells (RBC), white blood cells (WBC) and platelet abnormalities as well as coagulation disorders have been known to occur as sequelae of infection. The lab abnormalities as well as the resulting clinical effects of this deranged physiology in the setting of infection have long puzzled clinicians and have led to increased consultation from hematology service. We have attempted to consolidate the recently enlightened understanding of these changes and hope that it will translate into an improved patient care. Despite the decline in incidence of Human Immunodeficiency Virus (HIV) and improvements in drug therapy options (HAART), especially in the western population, hematological manifestations of HIV can be very extensive and warrant a separate chapter by itself. However we have included briefly some of the important hematological manifestations in an effort to make this article a comprehensive review.

Keywords: Red blood cells; White blood cells; Fibrinogen degradation products; Viral IL 6

Abbreviations: PT: Prothrombin Time; WBC: Disorders of White Blood Cells; MCD: Multicentric Castleman's Disease; TTP: Thrombotic Thrombocytopenic Purpura; HUS: Hemolytic Uremic Syndrome; aPTT: activated Partial Thromboplastin Time; FDP: Fibrinogen Degradation Products; AIDS: Acquired Immune Deficiency Syndrome; DIC: Disseminated Intravascular Coagulation.

\section{Disorders of Red Blood Cells}

Anemia: Globally, infectious diseases are arguably the most common cause of anemia. However, infectious disease is a less common cause of anemia in the western world. Anemia due to an infectious process can be classified as microcytic, macrocytic or normocytic. Normocytic anemia in an infectious context is typically due to acute blood loss. However, the anemia may transition to microcytic expression with continued blood loss due to the same infectious agent. Early malaria and babesiosis are a few examples of infectious states that can present with normocytic anemia.

\section{Normocytic Anemia}

Malaria: The global incidence of malaria was estimated to be 515 million with 2.2 billion people at risk for infection with Plasmodium falciparam alone in 2002 [1]. Severe malarial associated anemia is a common cause of death especially in children and pregnant women in endemic regions. Thus, the CDC advocated chemoprophylaxis for travelers to endemic regions. A total of 1,691 cases of malaria (including 1,688 cases classified as transported from other regions to the United States, one transfusion-related case, and two cryptic cases) was reported to the CDC with an onset of symptoms in 2010. This represents a $14 \%$ increase in reported cases when compared to the previous year [2]. Plasmodium falciparum, Plasmodium vivax, Plasmodium malariae, and Plasmodium ovale were identified in 58\%, 19\%, 2\%, and $2 \%$ of cases, respectively. Of the reported cases, $176(10 \%)$ were classified as severe infections and nine of these were fatal. Forty five of the cases (5\%) were reported as having followed and adhered to a chemoprophylactic drug regimen as recommended by CDC for the areas to which they had traveled. RBC's are the target cells of infection in malaria and most infections give rise to some form of anemia. The malarial parasites $P$. vivax and $P$. ovale have a strong affinity to infect the reticulocytes due to the greater expression of target receptor, the Duffy blood group antigen [3]. There is a resultant low parasitemia (1-2\%) and hemolysis is seen. $P$. malariae invades red blood cells of all ages, but parasite multiplication during each cycle is relatively low resulting in low parasitemia and mild symptoms.

P. falciparum invades RBC's of all ages, including early erythroblasts. Parasitemia is typically high and symptoms are severe for the non-immune western traveler. Anemia in this setting is classically normocytic and normochromic with notable absence of reticulocytes. In populations infected with P. falciparum, severe bone marrow suppression, respiratory distress, coma, and hypoglycemia can commonly occur. In addition to the destruction of infected RBC's in the setting of high parasitemia, approximately 8.5 uninfected red blood cells are removed from the circulation for each infected red blood cell that is removed [4]. The clearance of a high number of uninfected red blood cells is thought to be due to 
activation of reticuloend othelial system [5,6], splenic sequestration due to reduced deformability of uninfected RBC's [7], deposition of immunoglobulin and complement on uninfected RBCs resulting in a positive Direct Coombs test [8], and occasionally can be due to use of sulfa drugs in G6PD deficient patients. Cytokines and Hemozoin, a malarial pigment, are also thought to suppress the bone marrow and worsen the presentation of anemia [9]. Other factors that complicate the clinical picture of anemia in endemic countries include the presence of nutritional deficiencies, genetic traits like thalassemia, and concurrent infections such as HIV and/or other parasitic infections [10] (Figure 1).

Figure 1: Plasmodium vivax organisms: intraerythrocytic ring (short arrow); mature trophozoite (long arrow).

Babesiosis: Unlike malaria, babesiosis is a tick-borne protozoal disease that occurs principally in the United States and Europe. Seropositivity rates range from $4 \%-21 \%$ in the northeast United States. Most infected patients are asymptomatic, but mild cases may present with fever, chills, sweats, headache, myalgia, fatigue or arthralgia. The elderly and immunosuppressed, especially those with asplenia or with impaired cellular immunity, are more likely to become ill. In southern New England, onefourth of patients with babesiosis are co-infected with the Lyme disease and this cohort of patients also tends to have more severe illness. Diagnosis is made by blood smear exam and identification of the merozoites which forms the classic "Maltese Cross" during their asexual budding stage (Figure 2).

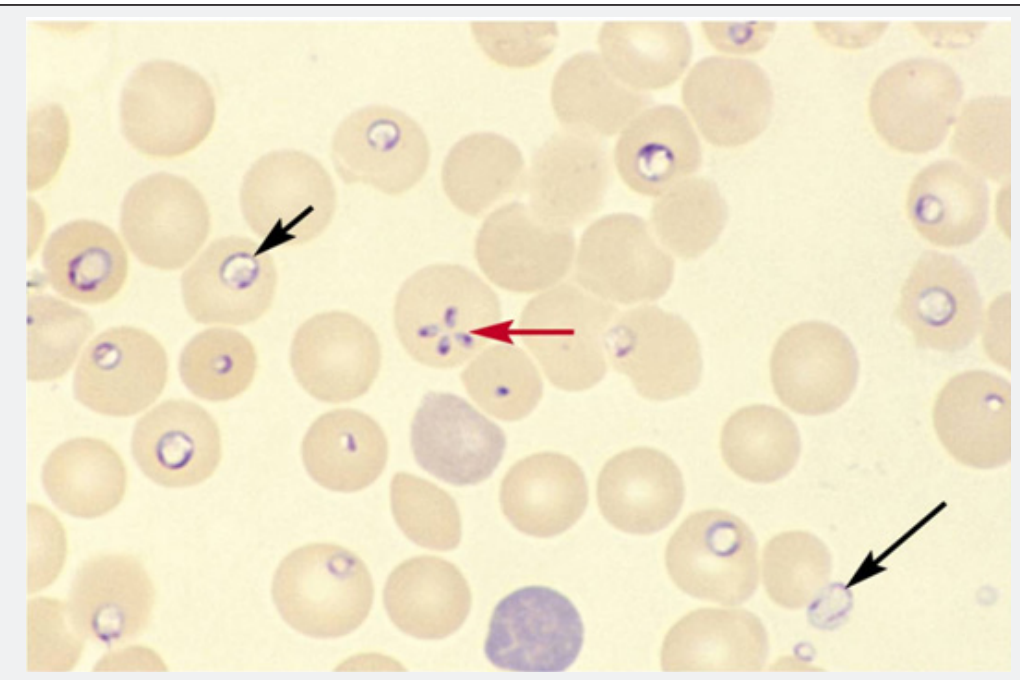

Figure 2: Babesia Microti forming intra-erythrocytic rings (short arrow), exo-erythrocytic rings (long arrow) and a "Maltese cross" (red arrow).

Bacterial: Non-immune hemolytic anemia occurs with Clostridium perfringens infection which results in very severe hemolysis and precipitous death has even been reported [11].
The alpha toxin phospholipase $\mathrm{C}$ is thought to be the hemolytic agent [12]. Haemophilus influenzae type B infection can also lead to hemolysis. The implicating agent in this situation is its capsular 
polysaccharide, polyribosyl ribitol phosphate. Immune hemolytic anemia, usually cold agglutinin disease, is more commonly seen in an infectious setting. Common precipitators would be Mycoplasma, Epstein-Barr Virus (EBV) and HIV. Varicella, Cytomegalovirus (CMV), Syphilis \& Listeria have been less commonly implicated. Other parasitic infections causing non-immune hemolytic anemia like Bartonellosis and Leishmaniasis are extremely rare in the United States.

Anemia of Chronic Infection: Infections are estimated to account for $18-95 \%$ of anemia of chronic disease [13]. Anemia in this setting is usually normocytic, but can be microcytic in severe cases. Cytokines released as a consequence of infection drive this process by direct bone marrow suppression [14], by inhibition of erythropoietin production [15], or by disruption of iron metabolism either directly [16] or through the production of Hepcidin in the liver $[17,18]$.

Microcytic Anemia: Microcytic anemia secondary to infectious diseases can be due to a severe form of anemia of chronic disease or secondary to chronic blood loss. Chronic blood loss can be sequelae of feco-oral transmitted helminthic infections such as Ancylostoma Duodenale, Necator americanus, Ascaris lumbricoides, Trichuris Trichiura, or Enterobius Vermicularis. Hookworm infections are acquired through direct larval penetration of the skin. Hence, hookworm can be seen in travelers to endemic regions who may take adequate sanitary precautions, but choose to walk barefoot on the beaches. Tapeworm infection can be prevented in travelers by ensuring meat is properly cooked, especially in countries where livestock are kept close to human feces.

Macrocytic Anemia: What should have been a closed chapter in medicine is now resurrected due to worldwide recent popularity of Sushi and Sashimi [19]. Diphyllobothrium latum and D. nihonkaiense are fish tape worms that can be transmitted through the consumption of raw or undercooked fish. Historically the fish tapeworms have been more common in Scandinavian countries, but now cases are being reported in North and South
America, Japan, as well as non-endemic regions of Europe. This may be in part to expansion of worldwide sales of fresh or frozen Pacific Salmon. Cases appear to be most commonly associated with Pacific Salmon, but can also be found in perch, char and pike [20]. D. latum has a unique affinity for Vitamin B12 and in 40\% of infected individuals there may be low Vitamin B12 causing pernicious macrocytic anemia.

\section{Disorders of White Blood Cells (WBC)}

Leukocytosis is a typical response to bacterial infections. Paradoxical leukopenia can occasionally be seen. Neutropenia was reported in $24.6 \%$ and lymphopenia was reported in $75.8 \%$ of patients with Typhoid in one study [21]. 44.5\% of patients were noted to have evidence of bone marrow suppression resulting in $31.3 \%$ with peripheral cytopenias and $8.3 \%$ with frank pancytopenia. Though exact mechanism is unclear, endotoxin release and cytokines resulting in bone marrow suppression and neutrophil margination is believed to be the cause. Similar observations have been made in tuberculosis, Shigella and Brucellosis. In one study, there was leukopenia in $15 \%$, thrombocytopenia in $23 \%$, and lymphopenia in $87 \%$ of patients with miliary tuberculosis [22]. Ehrlichiosis \& anaplasmosis are two separate tick-borne bacterial diseases with similar clinical and laboratory findings. CDC reporting of anaplasmosis in 2008 had increased threefold and reporting of ehrlichiosis had increased more than fourfold in 2008 when compared to 2000 [23]. Anaplasmosis targets neutrophils and ehrlichiosis targets mononuclear cells causing $50-90 \%$ of patients to have leucopenia $[24,25]$. Around 3000 cases $(2,000$ cases of ehrlichiosis and 1,000 cases of anaplasmosis) are now reported annually with a mortality rate of $1 \%$ for anaplasmosis and $3 \%$ for ehrlichiosis [26]. Suspicion should be high when a febrile patient with leukopenia or thrombocytopenia has been exposed to ticks in an endemic area. The peripheral blood smear should be examined for intracytoplasmic inclusions (morulae) within mononuclear cells for ehrlichiosis and within neutrophils for anaplasmosis (Figure 3).

Figure 3: Morula of Anaplasma phagocytophilum in the cytoplasm of the neutrophil (arrow). 
Leukopenia associated with viral infections is well understood in the community. However, in addition to considering HIV, EBV, CMV, Hepatitis viruses, Human herpes virus 6, Yellow fever and Colorado tick virus, viral exanthematous diseases such as Varicella, Measles and Rubella should also be considered while evaluating a febrile patient without obvious cause for leukopenia. The underlying mechanisms include splenomegaly, cytokine related marrow suppression and development of anti-neutrophil antibodies [27]. Parvovirus and Colorado tick virus are known to infect and destroy the hemopoietic progenitor cells [28]. EBV infection in the adolescent population can result in acute infectious mononucleosis which is associated with lymphocytosis with a large proportion of atypical lymphocytes with large irregular nuclei. These are essentially reactive CD8+ T cells and NK cells. EBV acquired during childhood years is often subclinical and hence not a problem in the developing world where $100 \%$ of children by age 4 are seropositive. Transient lympadenopathy is common with several viral disorders. Human herpes virus 8 is associated with multicentric castleman's disease (MCD), a lymphoproliferative disorder often mimicking lymphoma. HHV 8 infection can be seen in $100 \%$ of HIV + MCD and 40-50\% HIV MCD. HHV8 genome encoded viral IL 6 is the pathophysiological basis for the disease. It is responsible for leukopenia, anemia \& severe B symptoms. Viral IL-6(vIL-6) does not require the cellular IL-6 receptor for binding to the ubiquitously expressed gp130 receptor subunit and subsequent JAK-STAT signaling. Thus, in contrast to IL-6, vIL-6 can stimulate virtually all cells in the body
[29]. Early results with antiviral strategies have shown promising results [30].

\section{Disorders of Platelets}

\section{Thrombocytopenia}

Thrombocytopenia can be either from decreased production or increased destruction of platelets. Decreased production has been observed in those who have Dengue, Parvovirus, Rubella, Mumps, Varicella, Hepatitis C, Epstein-Barr virus, etc. Direct megakaryocytic infection has been demonstrated in Parvovirus, HIV and Dengue [31]. Viral infection can precipitate Immune Thrombocytopenic Purpura (ITP) and eradication of CMV with antiviral therapy has been shown to improve ITP in patients with active CMV infection [32]. Increased destruction is often seen with hemorrhagic fevers. Nonspecific antibody production with cross reactivity to platelets has been implicated in Dengue and HIV-1. Disseminated intravascular coagulation (DIC) is thought to underlie the hemorrhagic features of Rift Valley, Marburg and Ebola fevers. Release of tissue factor from monocytes and macrophages infected with Ebola virus are thought to be the cause for coagulation irregularities reported in Ebola hemorrhagic fever [33]. In most viral hemorrhagic fevers, the etiology of thrombocytopenia \& coagulopathy is more likely multifactorial with hepatic damage (site of production of thrombopoietin), consumptive coagulopathy, and primary marrow dysfunction all playing a role (Figure 4).

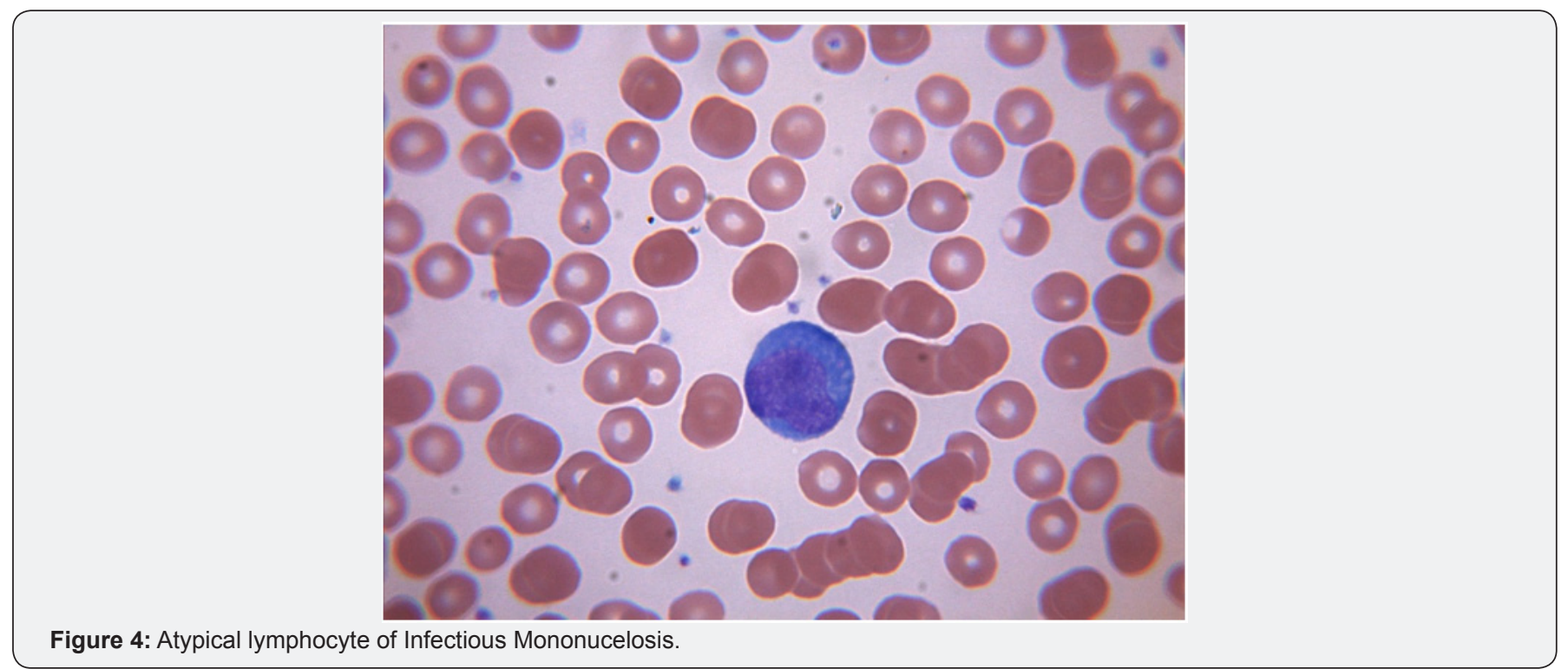

\section{Pancytopenia and Infection}

Transient pancytopenia can be seen with any viral or bacterial disease secondary to cytokine release. Severe and sustained pancytopenia can be seen in Parvovirus B19, HIV and Hepatitis virus infections. In addition to Hepatitis A,B,C and G, a yet unidentified hepatitis virus seems to account for $5 \%$ of cases of aplastic anemia in western countries [34] and 4 to 10 percent in the Far East [35]. It usually affects boys and young men and aplasia develops months after acute hepatitis. About $15 \%$ of children with seronegative acute liver failure developed bone marrow failure in one single institution study [36]. Parvovirus B19 is well known for its role in aplastic anemia, transient aplastic crisis is in those with chronic hemolytic disorders and chronic pure red blood cell aplasia in immunocompromised individuals. Even though it can infect the mature RBC's, full viral replication 
can only occur in the erythroid CFU's [37]. Globoside, P blood group antigen, is necessary for cell entry and infection and hence those lacking it are protected. Cessation of RBC production and drop in hematocrit follows infection and returns to normal in 10 to 14 days with clearance of infection. In patients unable to control Parvovirus infection either due to immunosupression or immunodeficiency, prolonged cessation of RBC production and consequently chronic pure red cell aplasia follows. Characteristic giant proerythroblast can be seen on bone marrow biopsy.

\section{Coagulation Disorders TTP/HUS}

Thrombotic thrombocytopenic purpura-hemolytic uremic syndrome (TTP-HUS) is best described as an acute syndrome with abnormalities in multiple organ systems. Presenting features include thrombocytopenia, microangiopathic hemolytic anemia, neurologic and renal abnormalities. When renal abnormalities are dominant, with or without neurological abnormalities, it is considered by some as hemolytic uremic syndrome (HUS) [38]. HUS is more common in children and rare in adults. It is also called Typical HUS or diarrhea associated HUS as most cases are due to Shiga-toxin-producing E.coli bacteria (most commonly 0157:H7 strain). A recent German outbreak was the result of a new strain of E. coli 0104:H4 which accounted for about 20\% HUS cases in adults [39]. There are various ways through which this process can occur. Direct endothelial damage and platelet aggregation from shiga toxin is considered the most common mechanism. There are also studies suggesting shiga toxin mediated antibodies against ADAMTS 13 [40]. Worsening of HUS symptoms in patients who were treated with antibiotics is considered a direct result of an increase in the release of shiga toxin due to bactericidal effect of the drug [41]. Even though most cases are due to Shiga Toxin producing Ecoli, there have been case reports of patients developing HUS after pneumococcal infection and HIV [42].

\section{Disseminated Intravascular Coagulation (DIC)}

Sepsis from both bacterial and non-bacterial infection is one of the most common causes for DIC [43]. What was initially described as a complication of endothelial damage by meningococcemia, has now been described in a variety of gram negative, gram positive and, very rarely, viral infections. About 30 to $40 \%$ of patients with gram negative sepsis are said to develop overt DIC [44]. Laboratory findings that are hallmark of acute DIC are thrombocytopenia, prolonged prothrombin time (PT), activated partial thromboplastin time (aPTT), elevated D-Dimer or fibrinogen degradation products (FDP) and reduced plasma fibrinogen level. A peripheral blood smear will show presence of microangiopathy. Other findings include prolonged thrombin time and reduced levels of antithrombin (AT), protein C, protein S, factor V and Factor VIII. However, in chronic DIC these values are variable as there is a slower rate of consumption of coagulation factors and there also may be an enhanced synthesis of these proteins. Hence, thrombocytopenia may be mild with fibrinogen level, PT and aPTT may be within normal range. In these patients, the diagnosis is often difficult and relies mainly upon findings of microangiopathy on the peripheral blood smear and elevated levels of FDPs and D-dimer [45].

Pathogenesis of the endotoxin-induced DIC involves both thrombin generation and suppression of normal antithrombotic mechanisms along with down regulation of the protein $\mathrm{C} /$ thrombomodulin system and perhaps impaired fibrinolysis. The extrinsic pathway seems to be the primary activating pathway; however, there is also activation of factor XII of the intrinsic pathway, which leads to release of kinins into circulation causing increased vascular permeability, vasodilatation and shock [46]. The balance between thrombin generation, clotting factor depletion, and thrombolysis determines the clinical presentation (ie, bleeding or thrombosis). Activation of the coagulation system due to endothelial damage and enhanced release of pro-coagulant substances may be due to a direct action of endotoxin and membrane lipopolysaccharides or indirectly through activation of cytokines like interleukin-6 and tumor necrosis factor alpha [47].

\section{Hematological manifestations of HIV}

Cytopenias of all cell lines were seen after HIV and acquired immune deficiency syndrome (AIDS) were defined. The direct correlation of the degree of cytopenias and its association with morbidity and mortality was soon recognized. Anemia was the most common cytopenia followed by lymphopenia, neutropenia and thrombocytopenia. Coagulation disorder in the form of TTPHUS and thrombophilia also have been described extensively. As mentioned in the beginning of this article, hematological manifestation of HIV infection is extensive and complex and warrants a separate chapter or review by itself. We have described the various manifestations and its causes briefly for a quick summation.

Anemia: Anemia is the most common hematological disorder seen in patients with HIV. In addition, the incidence of anemia increases with disease progression [48]. A large epidemiological study involving 2056 women infected with HIV identified 4 risk factors for developing anemia: CD4 count < 200/ microL, HIV 1-viral load of $>50,000 / \mathrm{ml}, \mathrm{MCV}<80 \mathrm{fl}$ and use of AZT in the preceding 6 months $[48,49]$. Even though HAART has shown to reduce the incidence and degree of anemia in all ages, anemia is independently associated with increased morbidity and mortality. The etiology of anemia in HIV is multifactorial. Opportunistic infection (fungal, bacterial, viral), nutritional causes (B12 and folic acid deficiency) abnormal iron metabolism, lymphoproliferative disorders, and medications are some of the common causes for anemia $[50,51]$.

Hemolysis which could be antibody mediated, drug induced or microangiopathic has been described in patients with HIV. Even though patients with HIV tend to test positive on direct coombs test at a higher percentage compared to normal subjects (18-43\%), overt hemolysis is uncommon [52]. Both warm and cold hemolytic anemia are described, and when present, the antibodies are most commonly directed against $u$ and $i$ antigens on 
the red blood cells [53]. Drug induced bone marrow suppression and rarely hemolysis are also some of the major causes of anemia. Ribavirin, used in treatment of patients with Hepatitis C coinfection, has been observed to cause severe hemolysis $[54,55]$. AZT is associated with dose dependent bone marrow suppression which usually develops within 1-2 weeks of initiation of therapy. Anemia is usually macrocytic and is due to inhibition of nucleic acid synthesis [56]. Other drugs like Ganciclovir, Trimethoprimsulfamethoxazole, Flucytosine, Amphotericin B, Pyrimethamine, Primaquine, Dapsone, Trimetrexate, and Interferon that are used in HIV related complications often worsen the anemia.

\section{Role of HIV}

Even though considered controversial, infection of the CD 34+ progenitor cells directly by HIV that then affects hematopoiesis, is increasingly being described as a possible mechanism of anemia in this setting. Retroviral infection has been clearly demonstrated in CD4+ lymphocytes, macrophages, monocytes, and follicular dendritic cells but to a lesser extent in CD34+ progenitor cells [57].

\section{Disorders of WBC}

Neutropenia: Neutropenia is seen in 5 to $10 \%$ in the early, asymptomatic infection and 50 to $70 \%$ of patients with advanced disease. Anti-neutrophil antibodies are detected in 1 out of 3 patients, but presence of antibodies does not correlate with the ANC [58]. Autoimmune destruction is not thought to play an important role. Antibody production is secondary to the immune dysregulation and hyperglobulinemia.

Lymphopenia: Lymphopenia is universal. HIV infection leads to severe depletion of CD4 T cells (primary target). CD4 cells are reduced precipitously in acute HIV infection and usually rebound over several weeks as HIV-specific CD8 T cells help to lower plasma viremia. Left untreated, CD4 $\mathrm{T}$ cells subsequently decline over several years. Antiretroviral therapy helps maintain CD4 levels.

Platelet Disorders: Thrombocytopenia affects 40 percent of patients during the course of their illness and in about $10 \%$ of patients thrombocytopenia can be an initial manifestation [59]. As with anemia, incidence of thrombocytopenia increases as the disease progresses, but can present at any point during the course of the disease. Thrombocytopenia appears to be more pronounced in patients who have uncontrolled viral replication and co-infection of Hepatitis C with underlying cirrhosis [60]. Primary HIV-associated thrombocytopenia (PHAT) is the most common cause of low platelet counts in HIV-infected patients. It resembles ITP except that patients with PHAT tend to have splenomegaly and less pronounced thrombocytopenia with spontaneous recovery [61]. Thrombocytopenia in HIV patients is due to a combination of reasons including a shortening of platelet life span, the doubling of splenic platelet sequestration, and the ineffective delivery of viable platelets to the peripheral blood despite a threefold thrombopoietin (TPO) driven expansion in marrow megakaryocyte mass. This was believed to be a result of direct impairment in platelet formation by HIV-infected marrow megakaryocytes [62].

Other secondary causes of thrombocytopenia can be attributed to underlying opportunistic infections (viral, bacterial, parasitic and fungal), malignancy, and co-morbid conditions that result in hypersplenism. Patients with HIV infection are also at risk for medication induced thrombocytopenia. In a retrospective study, it was noted that in patients exposed to either unfractionated heparin (UFH) or low molecular weight heparin (LMWH) those with HIV had a higher incidence of heparin induced thrombocytopenia (HIT) when compared to HIV negative patients [63]. It was also noted in the same study that there was reduced incidence of HIT with LMWH as compared to UFH [64]. In any patient receiving anticoagulation frequent monitoring of platelet counts is advised given the higher risk for developing HIT. Rarely thrombocytopenia in HIV infected patients can present as a manifestation of TTP- HUS. Even though the mechanism is largely unknown, TTP - HUS should be considered as a part of initial work up for thrombocytopenia and in HIV infected patients presenting with low platelets.

\section{Coagulation Disorders in HIV}

Several coagulation disorders can be seen in patients infected with HIV. Opportunistic infections, malignancy and use of certain drugs (eg. megace) increase the thrombotic risk in these patients. Lower CD 4 counts, elevated HIV viral load, presence of indwelling central venous catheter, presence of antiphospholipid antibodies, autoimmune hemolytic anemia, and acquired deficiencies of protein $\mathrm{C}$ and $\mathrm{S}$ and antithrombin are a few of the other risk factors associated with increased thrombotic risk in patients infected with HIV [65-68].

\section{Conclusion}

We realize that the differential diagnosis for hematological abnormalities can be extensive and complex. In this article we attempt to help the readers recognize that infectious disease is among the most common cause of these abnormalities. To describe these changes and also the underlying mechanism in detail, undoubtedly warrants a textbook in itself. We hope this article provides a comprehensive but a quick review of these changes and an insight to the underlying pathophysiology. Also given the nature of globalization and increase in human travel across various geographical regions, physicians today are more likely to encounter more uncommon causes for hematological abnormalities than ever before. This makes it even more challenging for the physician to diagnose and provide appropriate care at the right time. This article tries to incorporate all these factors for the reader to be aware of the various causes, even though the entity may be rare to that particular geographic location. 


\section{Acknowledgment}

We sincerely thank Dr. Steve M. Blevins, MD, Department of Medicine, University of Oklahoma Health Sciences Center for providing illustrations of blood smears of Anaplasma, Babesia and Plasmodium.

\section{References}

1. Snow RW, Guerra CA, Noor AM, Myint HY, Hay SI (2005) The global distribution of clinical episodes of Plasmodium falciparum malaria. Nature 434: 214-217.

2. Sonja Mali MPH, S Patrick Kachur MD, Paul M Arguin MD (2012) Malaria Surveillance - United States, 2010. Morbidity and Mortality Weekly Report 61(SS02): 1-17.

3. Woolley IJ, Hotmire KA, Sramkoski RM, Zimmerman PA, Kazura JW (2000) Differential expression of the duffy antigen receptor for chemokines according to RBC age and FY genotype. Transfusion 40(8): 949-953.

4. Jakeman GN, Saul A, Hogarth WL, Collins WE (1999) Anaemia of acute malaria infections in non-immune patients primarily results from destruction of uninfected erythrocytes. Parasitology 119(Pt_2): 127133.

5. Mohan K, Dubey ML, Ganguly NK, Mahajan RC (1995) Plasmodium falciparum: role of activated blood monocytes in erythrocyte membrane damage and red cell loss during malaria. Exp Parasitol 80(1): 54-63.

6. Brown AE, Webster HK, Teja Isavadharm P, Keeratithakul D (1990) Macrophage activation in falciparum malaria as measured by neopterin and interferon-gamma. Clin Exp Immunol 82(1): 97-101.

7. Dondorp AM, Angus BJ, Hardeman MR, Chotivanich KT, Silamut K, et al (1997) Prognostic significance of reduced red blood cell deformability in severe falciparum malaria. Am J Trop Med Hyg 57(5): 507-511.

8. Facer CA, Bray RS, Brown J (1979) Direct Coombs antiglobulin reactions in Gambian children with Plasmodium falciparum malaria. I. Incidence and class specificity. Clin Exp Immunol 35(1): 119-127.

9. Giribaldi G, Ulliers D, Schwarzer E, Roberts I, Piacibello W, et al. (2004) Hemozoin- and 4-hydroxynonenal-mediated inhibition of erythropoiesis. Possible role in malarial dyserythropoiesis and anemia. Haematologica 89(4): 492-493.

10. Calis JC, Phiri KS, Faragher EB, Brabin BJ, et al. (2008) Severe anemia in Malawian children. N Engl J Med 358(9): 888-899.

11. Rogstad B, Ritland S, Lunde S, Hagen AG (1993) Clostridium perfringens septicemia with massive hemolysis. Infection 21(1): 54.

12. J Sakurai, S Ochi, H Tanaka (1993) Evidence for coupling of Clostridium perfringens alpha-toxin-induced hemolysis to stimulated phosphatidic acid formation in rabbit erythrocytes. Infect Immun 61(9): 3711-3718.

13. Guenter Weiss MD, Lawrence T Goodnough MD (2005) Anemia of Chronic Disease. N Engl J Med 352(10): 1011-1023.

14. Wang CQ, Udupa KB, Lipschitz DA (1995) Interferon-gamma exerts its negative regulatory effect primarily on the earliest stages of murine erythroid progenitor cell development. J Cell Physiol 162(1): 134-138.

15. Jelkmann W (1998) Proinflammatory cytokines lowering erythropoietin production. J Interferon Cytokine Res 18(8): 555-559.

16. Ludwiczek S, Aigner E, Theurl I, Weiss G (2003) Cytokine-mediated regulation of iron transport in human monocytic cells. Blood 101(10): 4148-4154.
17. Nemeth E, Rivera S, Gabayan V (2004) IL-6 mediates hypoferremia of inflammation by inducing the synthesis of the iron regulatory hormone hepcidin. J Clin Invest 113(9): 1271-1276.

18. Nicolas G, Bennoun M, Porteu A (2002) Severe iron deficiency anemia in transgenic mice expressing liver hepcidin. Proc Natl Acad Sci, USA 99(7): 4596-4601.

19. Craig N (2012) Fish tapeworm and sushi. Can Fam Physician 58(6): 654-658.

20. Arizono N, Yamada M, Nakamura Uchiyama F, Ohnishi K (2009) Diphyllobothriasis associated with eating raw Pacific salmon. Emerg Infect Dis 15(6): 866-870.

21. Abdool Gaffar MS, Seedat YK, Coovadia YM, Khan Q (1992) The white cell count in typhoid fever. Trop Geogr Med 44(1-2): 23-27.

22. Maartens G, Willcox PA, Benatar SR (1990) Miliary tuberculosis: rapid diagnosis, hematologic abnormalities, and outcome in 109 treated adults. Am J Med 89(3): 291-296.

23. Centers for Disease Control and Prevention (CDC) (2009) Anaplasmosis and ehrlichiosis - Maine, 2008. MMWR Morb Mortal Wkly Rep 58(37): 1033-1036.

24. Fishbein DB, Dawson JE, Robinson LE (1994) Human ehrlichiosis in the United States, 1985 to 1990. Ann Intern Med 120(9): 736-743.

25. Bakken JS, Krueth J, Wilson Nordskog C, Tilden RL, et al. (1996) Clinical and laboratory characteristics of human granulocytic ehrlichiosis. JAMA 275(3): 199-205.

26. Thomas, Rachael J, Dumler, J Stephen, Carlyon, et al. (2009) Current management of human granulocytic anaplasmosis, human monocytic ehrlichiosis and ehrlichiosis. Expert Review of Anti-infective Therapy 7(6): 709-722.

27. Chou TN, Hsu TC, Chen RM, Lin LI, Tsay GJ (2000) Parvovirus B19 infection associated with the production of anti-neutrophil cytoplasmic antibody (ANCA) and anticardiolipin antibody (aCL). Lupus 9(7): 551554 .

28. Philipp CS, Callaway C, Chu MC, Huang GH, Monath TP, et al. (1993) Replication of Colorado tick fever virus within human hematopoietic progenitor cells. J Virol 67(4): 2389-2395.

29. Suthaus J, Stuhlmann Laeisz C, Tompkins VS, Rosean TR, Klapper W (2012) HHV-8-encoded viral IL-6 collaborates with mouse IL-6 in the development of multicentric Castleman disease in mice. Blood 119(22): 5173-5181.

30. Casper C, Nichols WG, Huang ML, Corey L, Wald A (2004) Remission of HHV-8 and HIV-associated multicentric Castleman disease with ganciclovir treatment. Blood 103(5): 1632-1634.

31. Basu A, Jain P, Gangodkar SV, Shetty S, Ghosh K (2008) Dengue 2 virus inhibits in vitro megakaryocytic colony formation and induces apoptosis in thrombopoietin-inducible megakaryocytic differentiation from cord blood CD34+ cells. FEMS Immunol Med Microbiol 53(1): 4651.

32. DiMaggio D, Anderson A, Bussel JB (2009) Cytomegalovirus can make immune thrombocytopenic purpura refractory. Br J Haematol 146(1): 104-1012.

33. Geisbert TW, Young HA, Jahrling PB, Davis KJ, Kagan E, et al. (2003) Mechanisms underlying coagulation abnormalities in ebola hemorrhagic fever: overexpression of tissue factor in primate monocytes/macrophages is a key event. J Infect Dis 188(11): 16181629.

34. Locasciulli A, Bacigalupo A, Bruno B, Montante B, Marsh J, et al. (2010) Hepatitis-associated aplastic anaemia: epidemiology and treatment 
results obtained in Europe. A report of The EBMT aplastic anaemia working party. Severe Aplastic Anemia Working Party of the European Blood and Marrow Transplant Group (SAA-WP, EBMT). Br J Haematol 149(6): 890-895.

35. Young NS, Issaragrisil S, Chieh CW, Takaku F (1986) Aplastic anaemia in the Orient. Br J Haematol 62: 1-6.

36. Hadzic N, Height S, Ball S, Rela M, Heaton ND, et al. (2008) Evolution in the management of acute liver failure-associated aplastic anaemia in children: A single centre experience. J Hepatol 48: 68-73.

37.Yoto Y, Kudoh T, Suzuki N, Katoh S, Matsunaga Y, et al. (1993) Thrombocytopenia induced by human parvovirus B19 infections. Eur J Haematol 50(5): 255-257.

38. James N George (2010) How I treat patients with thrombotic thrombocytopenic purpura: 2010. George JN Blood 116(20): 40604069.

39. Frank C, Werber D, Cramer JP (2011) Epidemic profile of Shigatoxin-producing Escherichia coli 0104:H4 outbreak in Germany. HUS Investigation Team. N Engl J Med 365(19): 1771-1780.

40. Ray PE, Liu XH (2001) Pathogenesis of Shiga toxin-induced hemolytic uremic syndrome. Pediatr Nephrol 16(10): 823-839.

41. Wong CS, Jelacic S, Habeeb RL, Watkins SL, Tarr PI (2000) The risk of the hemolytic-uremic syndrome after antibiotic treatment of Escherichia coli 0157:H7 infections. N Engl J Med 342: 1930-1936.

42. Begue R, Dennehy PH, Peter GN (1991) Hemolytic uremic syndrome associated with Streptococcus pneumoniae. Engl J Med 325(2): 133134.

43. Van Gorp EC, Suharti C, Ten Cate H, Dolmans WM, Van Der Meer JW, et al. (1999) Review: infectious diseases and coagulation disorders. Brandjes DPJ Infect Dis 180(1): 176-186.

44. Gando S, Kameue T, Nanzaki S, Nakanishi Y (1996) Disseminated intravascular coagulation is a frequent complication of systemic inflammatory response syndrome. Thromb Haemost 75(2): 224-228.

45. Levi M, Toh CH, Thachil J, Watson HG (2009) Guidelines for the diagnosis and management of disseminated intravascular coagulation. British Committee for Standards in Haematology. J Haematol 145(1): 24-33.

46. Levi M, Ten Cate H (1999) Disseminated intravascular coagulation. N Engl J Med 341(8): 586-592.

47. Levi M, Van Der Poll T (1997) The cytokine-mediated imbalance between coagulant and anticoagulant mechanisms in sepsis and endotoxaemia. Eur J Clin Invest 27(1): 3-9.

48. Sullivan PS, Hanson DL, Chu SY, Jones JL, Ward JW (1998) Epidemiology of anemia in human immunodeficiency virus (HIV)-infected persons: results from the multistate adult and adolescent spectrum of HIV disease surveillance project. Blood 91(1): 301-308.

49. Berhane K, Karim R, Cohen MH, Masri Lavine L, Young M, Anastos K, Augenbraun M, Watts DH, Levine AM (2004) Impact of highly active antiretroviral therapy on anemia and relationship between anemia and survival in a large cohort of HIV-infected women: Women's Interagency HIV Study. J Acquir Immune Defic Syndr 37(2): 12451252.

50. Hepburn MJ, Dyal K, Runser LA, Barfield RL, Hepburn LM, et al. (2003) Low serum vitamin B12 levels in an outpatient HIV-infected population. Int J STD AIDS 15(2): 127-133.

51. Sproat LO, Pantanowitz L, Lu CM, Dezube BJ (2003) Human immunodeficiency virus-associated hemophagocytosis with irondeficiency anemia and massive splenomegaly. Clin Infect Dis 37(11): e170-e173.
52. Toy PT, Reid ME, Burns M (1985) Positive direct antiglobulin test associated with hyperglobulinemia in acquired immunodeficiency syndrome (AIDS). Am J Hematol 19(2): 145-150.

53. Lai M, Visconti E, D Onofrio G, Tamburrini E, Cauda R, et al. (2006) Lower hemoglobin levels in human immunodeficiency virus-infected patients with a positive direct antiglobulin test (DAT): relationship with DAT strength and clinical stages. Transfusion 46(7): 1237-1243.

54. Mc Ginniss MH, Macher AM, Rook AH, Alter HJ (1986) Red cell autoantibodies in patients with acquired immune deficiency syndrome. Transfusion 26(5): 405-409.

55. Zylberberg H, Benhamou Y, Lagneaux JL, Landau A, Chaix ML, et al. (2000) Safety and efficacy of interferon-ribavirin combination therapy in HCV-HIV coinfected subjects: an early report. Gut 47(5): 694-697.

56. Snower DP, Weil SC (1993) Changing etiology of macrocytosis. Zidovudine as a frequent causative factor. Am J Clin Pathol 99(1): $57-$ 60.

57. Richman DD, Fischl MA, Grieco MH, Gottlieb MS, Volberding PA, et al. (1987) The toxicity of azidothymidine (AZT) in the treatment of patients with AIDS and AIDS-related complex. A double-blind, placebocontrolled trial. N Engl J Med 317(4): 192-197.

58. Scadden DT, Zon LI, Groopman JE (1989) Pathophysiology and management of HIV-associated hematologic disorders. Blood 74(5): 1455-1463.

59. Murphy MF, Metcalfe P, Waters AH, Carne CA, Weller IV (1987) Incidence and mechanism of neutropenia and thrombocytopenia in patients with human immunodeficiency virus infection. Br J Haematol 66(3): 337-340.

60. Morris L, Distenfeld A, Amorosi E, Karpatkin Simon (1982) Autoimmune thrombocytopenic purpura in homosexual men. Intern Med 96(6_Pt_1): 714-717.

61. Marks KM, Clarke RM, Bussel JB, Talal AH, Glesby MJ (2009) Risk factors for thrombocytopenia in HIV-infected persons in the era of potent antiretroviral therapy. J Acquir Immune Defic Syndr 52(5): 595599.

62. Glatt AE, Anand A (1995) Thrombocytopenia in patients infected with human immunodeficiency virus: treatment update. Clin Infect Dis 21(2): 415-423.

63. Ballem PJ, Belzberg A, Devine DV, Lyster D, Spruston B, et al. (1992) Kinetic studies of the mechanism of thrombocytopenia in patients with human immunodeficiency virus infection. N Engl J Med 327(25): 17791784.

64. Cole JL, Marzec UM, Gunthel CJ, Karpatkin S, Worford L, et al. (1998) Ineffective platelet production in thrombocytopenic human immunodeficiency virus-infected patients. Blood 91(9): 3239-3246.

65. Thompson GR $3^{\text {rd }}$, Lawrence VA, Crawford GE (2007) HIV infection increases the risk of heparin-induced thrombocytopenia. Clin Infect Dis 45(10): 1393-1396.

66. Sullivan PS, Dworkin MS, Jones JL, Hooper WC (2000) Epidemiology of thrombosis in HIV-infected individuals. The Adult/Adolescent Spectrum of HIV Disease Project. AIDS 14(3): 321-324.

67. Abuaf N, Laperche S, Rajoely B, Carsique R, Deschamps A, et al. (1997) Autoantibodies to phospholipids and to the coagulation proteins in AIDS. Thromb Haemost 77(5): 856-861.

68. Klein SK, Slim EJ, De Kruif MD, Keller TT, Ten Cate H, et al. (2005) Is chronic HIV infection associated with venous thrombotic disease? A systematic review. Neth J Med 63(4): 129-136. 
This work is licensed under Creative Commons Attribution 4.0 License

DOI: 10.19080/JOJNHC.2018.08.555727

\section{Your next submission with Juniper Publishers} will reach you the below assets

- Quality Editorial service

- Swift Peer Review

- Reprints availability

- E-prints Service

- Manuscript Podcast for convenient understanding

- Global attainment for your research

- Manuscript accessibility in different formats ( Pdf, E-pub, Full Text, Audio)

- Unceasing customer service

Track the below URL for one-step submission https://juniperpublishers.com/online-submission.php 